\title{
ANALISIS KESALAHAN TEKS BUKU PENDIDIKAN BAHASA ARAB DI MADRASAH
}

\author{
Rizka A'yuna Fuadiyah, Mirwan Akhmad Taufiq \\ Universitas Islam Negeri Sunan Ampel Surabaya \\ email: rizka.ayunafuadiyah@yahoo.com
}

\begin{abstract}
This article describes Arabic language books' standard at the madrasah ibtidaiyah level (Islamic Elementary School). Error analysis on textbook is one of the methods to determine the standard of the book. This study aimed to uncover syntactic errors and make corrections to the Arabic language books used as teaching materials at the madrasah ibtidaiyah level. This research was conducted using qualitative methods; applied language approaches in the field of nahwu (syntax). The analysis technique used a collaboration of content analysis by Rusydi and al-Rajihi. The primary data source was done using documentation from the book "Fokus: Modul Bahan Ajar K13 Bahasa Arab Untuk Madrasah Ibtidaiyah Kelas 5A" and interviews with teachers. Secondary data sources were carried out using documentation from related literature studies. There were seven forms of syntax errors, including word order, idhofah arrangement, incorrect use of vocabulary, misuse of al-ta'rif, i'rab, dhamir, error in using a verb. These errors have been corrected by relying on Arabic grammar rules so that this textbook is recommended for revision.
\end{abstract}

Keywords: Text Analysis; Error Analysis; Arabic Language Books; Madrasah.

\begin{abstract}
Abstrak
Artikel ini mendeskripsikan tentang standar buku Pendidikan Bahasa Arab di tingkat madrasah. Analisis kesalahan teks merupakan salah satu metode untuk mengetahui standar buku tersebut. Tujuan dari penelitian ini adalah untuk mengungkap kesalahan sintaksis dan melakukan pembenahan pada buku bahasa Arab yang digunakan sebagai bahan ajar di tingkat Madrasah Ibtidaiyah.
\end{abstract}




\begin{abstract}
Penelitian ini dilakukan dengan metode kualitatif, pendekatan ilmu bahasa terapan, dalam bidang nahwu (syntax). Teknik analisa menggunakan kolaborasi analisis konten Rusydi dan al-Rajihi. Sumber data primer dilakukan dengan cara dokumentasi dari buku "Fokus: Modul Bahan Ajar K13 Bahasa Arab Untuk Madrasah Ibtidaiyah Kelas 5A" dan wawancara kepada pengajar, sumber data sekunder dilakukan dengan cara dokumentasi dari studi kepustakaan terkait. Ditemukan tujuh bentuk kesalahan sintaksis, diantaranya: susunan kata, susunan idhofah, salah penggunaan kosa-kata, kesalahan penggunaan al ta'rif, i'rab, dhamir, kesalahan penggunaan fi'il. Kesalahan-kesalahan tersebut dilakukan pembetulan dengan bersandar pada kaidah gramatika bahasa arab, sehingga buku bahan ajar ini direkomendasikan untuk dilakukan revisi ulang.
\end{abstract}

Kata Kunci: Analisis Teks; Analisis Kesalahan; Buku Bahasa Arab; Madrasah.

\title{
A. Pendahuluan
}

Kualitas buku bahan ajar di madrasah menjadi salah satu faktor penentu untuk meraih Capaian Pembelajaran (CP) dalam proses kegiatan belajar dan mengajar. Standar kualitas itu tertuang pada Peraturan Menteri Pendidikan dan Kebudayaan RI nomor 8 tahun 2016. ${ }^{1}$ Sebab, buku bahan ajar menempati unsur pokok dalam kegiatan dan proses pembelajaran. CP yang berupa kemampuan pengetahuan, keterampilan dan sikap, akan sulit dicapai jika kualitas buku bahan ajar ini masih belum memiliki standarisasi. ${ }^{2}$ Chomsin berpandangan bahwa buku bahan ajar bertujuan untuk memperjelas dan mempermudah penyajian materi dengan harapan mampu membuat peserta didik lebih aktif belajar di kelas dan mandiri menuju ilmu atau keterampilan yang diharapkan. ${ }^{3}$ Nafi'ah juga mempertegas bahwa Modul merupakan bahan ajar berupa teks yang digunakan untuk membantu pengembangan siswa dalam proses pembelajaran. ${ }^{4}$ Maka, perlu kiranya ada sebuah evaluasi standarisasi buku bahan ajar, agar keberadaannya sudah sesuai dengan standar yang ditetapkan oleh permen pendidikan dan kebudayaan tersebut. ${ }^{5}$

${ }^{1}$ Menteri Pendidikan Dan Kebudayaan Republik Indonesia, “Peraturan Menteri Pendidikan Dan Kebudayaan Republik Indonesia Nomor 8 Tahun 2016 Tentang Buku Yang Digunakan Oleh Satuan Pendidikan" (2016).

${ }^{2}$ Annisa Anita Dewi, Buku Sebagai Bahan Ajar: Sebuah Perbandingan Buku Teks Bahasa Inggris di Indonesia dan di Thailand (Sukabumi: CV. Jejak, 2009), h. 37.

${ }^{3}$ Chomsin S. Widodo dan Jasmadi, Panduan Menyusun Bahan Ajar Berbasis Kompetensi (Jakarta: Kompas Gramedia, 2008), h. 43.

${ }^{4}$ Khotimatun Nafiah dan Retno Purnama Irawati, "Pengembangan Bahan Ajar Bahasa Arab Sebagai Penunjang Pembelajaran Tarakib (Qawaid) Kelas VII MTs Negeri 1 Semarang," Lisan Al-Arab : Journal of Arabic Language And Arabic Teaching 4, no. 1 (2015): 23-28, https://journal.unnes.ac.id/sju/index.php/laa/article/view/7628.

${ }^{5}$ R. Umi Baroroh dan Etika Riani Tsani, “Evaluasi Mahārah Al-Qirā’ah Dalam Buku Ajar Durūs Al-Lugah Al-'Arabiyyah Buku Siswa Bahasa Arab Pendekatan Saintifik Kurikulum 
Salah satu bentuk standarisasi buku bahan ajar adalah dengan menjaga isi atau konten terhindar dari kesalahan bahasa. Fisiak menegaskan, salah satu bentuk analisis konten adalah analisis kesalahan bahasa, yang terdapat tiga istilah; lapses, error dan mistake. Lapses adalah sebuah kesalahan berbahasa yang tidak disadari oleh penutur. Hal ini dikarenakan ia ingin mengubah konten bahasa sebelum konten pertama selesai dan sempurna. Error adalah kesalahan berbahasa yang disebabkan oleh penutur melanggar gramatikal bahasa karena faktor interferensi kaidah bahasa lain atau pandangan lain dalam satu bahasa yang sama. Sedangkan mistake adalah kesalahan berbahasa yang disebabkan oleh penutur karena salah dalam pemilihan kata, dan kurang tepat dalam menggunakan kaidah bahasa karena kurang penguasaan bahasa kedua (B2). ${ }^{6}$

Toto dan Fauzi telah melakukan analisis kesalahan sintaksis pada buku teks bahasa Arab tingkat perguruan tinggi agama Islam. Sampel yang digunakan adalah buku bahasa Arab yang diajarkan di Pusat Pengembangan Bahasa IAIN Surakarta, al-māhir fì taţbīqi al-kalām wa al-istimā'. Ditemukan beberapa kesalahan sintaksis dan merekomendasikan untuk segera direvisi konten kebahasaan buku tersebut, karena buku itu menjadi buku bahan ajar bahasa Arab. ${ }^{7}$ Ihdatul dan Syamsuddin juga telah melakukan hal yang sama, hanya fokus pada objek buku yang berbeda, yaitu Durūsu alLughah al-Arabiyah, karya Muhammad In'am. Buku ini lebih dikenal di pesantren, karena bukan buku bahan ajar yang ditetapkan di perguruan tinggi atau sekolah. Ditemukan beberapa kesalahan sintaksis dan merekomendasikan untuk segera direvisi. ${ }^{8}$ Alawiyah telah melakukan analisis terjemahan pada teks akademik mahasiswa program studi PBA UIN Syarif Hidayatullah. ${ }^{9}$ Fitria dan lain juga melakukan analisa kesalahan berbahasa fokus pada unsur fonologis bahasa untuk siswa kelas VII F SMP

2013 Kelas X Madrasah Aliyah," Al Mahāra: Jurnal Pendidikan Bahasa Arab 5, no. 1 (2019): 101, https://doi.org/10.14421/almahara.2019.051-06.

${ }^{6}$ Jacek Fisiak, "The Contrastive Analysis of Phonological Systems," John Benjamins Publishing Company, 1981, https://doi.org/10.1075/cilt.12.18fis.

7 Toto Suharto dan Ahmad Fauzi, "Analisis Kesalahan Sintaksis Dalam Buku Teks Bahasa Arab Untuk Perguruan Tinggi Keagamaan Islam," Arabiyat : Jurnal Pendidikan Bahasa Arab dan Kebahasaaraban 4, no. 1 (2017): 20-37, https://doi.org/10.15408/a.v4i1.5274.

${ }^{8}$ Ihdatul Hidayah dan Syamsuddin Asyrofi, "Analisis Kesalahan Sintaksis Pada Buku Teks Duru>Su Al-Lughah Al-Ara>Biyah 'Ala> Thoriqotial-Muba>Syarah Al-Muta>Kamilah Karya Muhammad In'Am, M.A," Al Mahāra: Jurnal Pendidikan Bahasa Arab 4, no. 2 (2018): 239, https://doi.org/10.14421/almahara.2018.042-05.

${ }^{9}$ N. Lalah Alawiyah, Ahmad Royani, dan Mukhshon Nawawi, “Analisis Terjemahan Teks Akademik Mahasiswa Program Studi Pendidikan Bahasa Arab," Arabiyat : Jurnal Pendidikan Bahasa Arab dan Kebahasaaraban 3, no. 2 (2016): 217, https://doi.org/10.15408/a.v3i2.4642. 
Plus Baiturrahman 2. Penelitian ini mengambil sampel tindak tutur berbahasa Arab bukan teks bahasa Arab pada sebuah buku. ${ }^{10}$

Beberapa penelitian tersebut, semuanya menggunakan analisis teks bahasa pada buku atau tutur bahasa. Penelitian yang fokus pada analisis sintaksis hanya ada dua, buku bahasa Arab di PT dan buku bahasa Arab di pesantren. Pada penelitian ini fokus menganalisis buku bahan ajar Bahasa Arab Untuk Madrasah Ibtidaiyah kelas 5A. Buku ini terdiri atas tiga bab, mencakup empat keterampilan berbahasa Arab (maharoh; istima, kalam, qira'ah dan kitabah) yang dipaparkan secara sistematis. Buku ini juga dilengkapi dengan gambar dan kamus kosakata sederhana untuk membekali siswa memahami teks pada materi-materi selanjutnya, yang mengikuti Kurikulum 13 (K13). Penulisnya adalah Puji Prihwanto, seorang sarjana sosiologi islam di Sekolah Tinggi Agama Islam Negeri (STAIN) Surakarta, dengan editor Amiruddin Fattah, tanpa keterangan tahun dan nomor urutan cetak, namun memiliki ISBN: 978-602-442-353-7 (jilid lengkap) 978-602442-362-9, dan diterbitkan oleh CV. Sindunata. ${ }^{11}$

Berdasarkan analisis awal terhadap buku bahan ajar itu, telah ditemukan beberapa kesalahan sintaksis, misalnya pada penulisan في غرفةُ المذاكرة. Pada susunan ini terdapat kesalahan sintaksis yang terletak pada kesalahan i'rob, yaitu harakat dhummah yang terdapat pada kata غرفة, padahal kata itu majrur (dibaca i'rab jar) dengan huruf jar; fi. Penulisan yang tepat sesuai dengan kaidah bahasa Arab adalah في غرفِة الدذاكرة dengan jar; dengan tanda kasrah. Adapun kesalahan sintaksis yang lain terdapat pada ketidaktepatan harakat

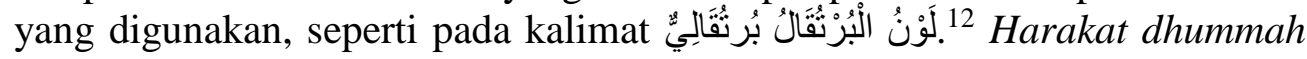
pada huruf lam al-burtuqālu tidak benar. Jenis kesalahan ini tergolong pada kesalahan sintaksis, di mana kata al-burtuqālu sendiri merupakan sebuah kata yang berkedudukan sebagai mudhaf ilaih dengan mudhaf berupa kata launu. Seharusnya mudhaf ilaih itu berkedudukan i'rob jar, pada kata ini dengan alamat kasrah.

Buku ini merupakan salah satu buku acuan pembelajaran bahasa Arab di Madrasah Ibtidaiyah. Di dalamnya masih ditemukan kesalahan-kesalahan sintaksis yang menyalahi kaidah bahasa Arab baku (fusha). Sebagai buku acuan dalam pembelajaran bahasa Arab, seharusnya sudah melewati koreksi yang ketat dan menghindari kesalahan-kesalahan sintaksis di atas. Sehingga buku ajar Bahasa Arab, termasuk Fokus, dapat digunakan oleh peserta didik

\footnotetext{
${ }^{10}$ Fitria Lathifah, Syihabuddin Syihabuddin, dan M. Zaka Al Farisi, "Analisis

Kesalahan Fonologis Dalam Keterampilan Membaca Teks Bahasa Arab," Arabiyat : Jurnal Pendidikan Bahasa Arab dan Kebahasaaraban 4, no. 2 (2017): 174, https://doi.org/10.15408/a.v4i2.6273.

${ }_{11}$ Puji Prihwanto, Fokus: Modul Bahan Ajar K13 Bahasa Arab Untuk Madrasah Ibtidaiyah Kelas 5A (Surakarta: CV. Sindunata, 2017).

12 Prihwanto, 112.
} 
dan guru sebagai rujukan dalam mengajarkan bahasa Arab di tingkat Madrasah Ibtidaiyah. Melihat kekurangan itu, peneliti melakukan tinjauan teks bahasa Arab pada buku tersebut, dengan teori analisa konten pada ranah $\operatorname{syntax}$ (nahwu).

Maka, fokus penelitian ini pada dua hal; (1) menemukan kesalahan teks bahasa Arab dan (2) membenarkan (taswib) kesalahan tersebut agar sesuai dengan kaidah Nahwu bahasa Arab yang terdapat pada "Fokus: Modul Bahan Ajar K13 Bahasa Arab Untuk Madrasah Ibtidaiyah Kelas 5A". Apabila ditemukan kesalahan-kesalahan dapat dilakukan revisi, sehingga pada terbitan mendatang sudah terhindar dari kesalahan bahasa. Alasan teoritis penelitian ini dilakukan juga untuk menghindari kesalahan berjamaah bagi siswa-siswi Madrasah Ibtidaiyah di bawah naungan Kementerian Agama RI. Acuan Kementerian Agama RI tidak hanya pada buku itu saja, masih ada beberapa buku cetak lainnya, hanya saja jika buku ini dibiarkan salah akan berpengaruh pada pendidikan bahasa Arab di tingkat madrasah di Indonesia. Hal ini juga untuk menghindari persepsi 'salah' dianggap benar oleh para siswa dan siswi, karena mereka baru awal-awal mempelajari bahasa Arab. Sehingga, cetakan-cetakan selanjutnya agar mendapat perhatian lebih dari pihak-pihak terkait pemegang kebijakan.

\section{B. Metode Penelitian}

Penelitian ini dilakukan dengan metode kualitatif (qualitative research), fokus pada pendekatan Linguistik Terapan, bidang analisis kesalahan dari sisi kaidah bahasa Arab (nahwu/syntax). Terdapat empat unit objek analisis kesalahan dalam bahasa Arab; fonology, morphology, syntax dan semantic. Peneliti memfokuskan kajian ini pada objek syntax pada buku tersebut. Karena sintaksis menjadi unsur terpenting dalam pembelajaran bahasa Arab. Ucapan bahasa Arab akan sulit dipahami jika tidak sesuai dengan kaidah tata bahasa Arab yang benar. Kaidah inilah yang membahas hubungan antar kata dalam kalimat, dalam disiplin ilmu bahasa Arab identik dengan istilah 'nahwu'. Kaidah nahwu ini dijadikan barometer keabsahan seseorang dalam berbicara bahasa Arab fusha dengan baik dan benar. Mengetahui kaidah nahwu menjadi penting bagi siapa saja yang akan berbicara atau menulis bahasa Arab, terutama bagi masyarakat non-Arab dalam pembelajaran bahasa Arab. ${ }^{13}$ Ihda menjelaskan bahwa sintaksis berpusat pada pembahasan antara hubungan satu kata dengan kata lain, sehingga menjadi satu kesatuan kalimat yang dapat dipahami dengan benar. Fungsi sintaksis memainkan peran pada setiap kata dalam sebuah kalimat, letak pada perubahan akhir kata, yang kemudian disebut dengan i'rab. Terdapat 3 bagian sintaksis di

${ }^{13}$ Nafiah dan Irawati, "Pengembangan Bahan Ajar Bahasa Arab Sebagai Penunjang Pembelajaran Tarakib (Qawaid) Kelas VII MTs Negeri 1 Semarang," 24. 
dalam bahasa Arab; isim/ kata atau kata benda, fi'il/ kata kerja dan huruf/pelengkap. ${ }^{14}$

Teknik pengumpulan data primer dilakukan dengan cara dokumentasi dan wawancara. Dokumentasi dilakukan untuk mengkaji teks-teks bahasa Arab yang terdapat pada buku Bahasa Arab Untuk Madrasah Ibtidaiyah kelas 5 tersebut. Wawancara dilakukan dengan para pengajar bahasa Arab di madrasah yang menggunakan buku ini. Adapun data sekunder dikumpulkan dengan cara dokumentasi dari data-data kepustakaan, yaitu dengan mengkaji buku dan artikel yang mengkaji tentang analisis kesalahan dan kaidah-kaidah bahasa Arab. Metode analisis data yang digunakan dalam penelitian ini adalah analisis isi atau content analysis, sebuah metode penelitian dengan menggunakan seperangkat prosedur untuk membuat inferensi yang valid dari teks. ${ }^{15}$ Teknis analisis yang digunakan adalah gabungan teknik Rusydi dan al-Rajihi. Rusydi membagi tiga langkah teknik analisis kesalahan; (1) Mengidentifikasi kesalahan, (2) Mendeskripsikan kesalahan. (3) Penafsiran kesalahan. Al-Rajihi menambahkan satu langkah lagi, yaitu (4) Perbaikan kesalahan. Menurutnya analisis kesalahan tidak cukup hanya dalam lingkup mengidentifikasi dan menafsirkan kesalahan saja, melainkan perlu adanya upaya perbaikan dan pemberian solusi dari kesalahan-kesalahan tersebut. ${ }^{16}$ Empat langkah itu menjadi panduan teknik analisis kesalahan teks.

\section{Hasil Penelitian dan Pembahasan}

\section{Buku Pendidikan Bahasa Arab "Fokus"}

Buku ini berjudul "Fokus: Modul Bahan Ajar K13 Bahasa Arab Untuk Madrasah Ibtidaiyah Kelas 5A". Buku ini merupakan buku bahan ajar yang digunakan pada pembelajaran bahasa Arab kelas 5 Madrasah Ibtidaiyah. Setelah dilakukan penelusuran ditemukan fakta bahwa buku ini tidak hanya terdapat materi pelajaran bahasa Arab saja, namun juga terdapat beberapa materi mata pelajaran di antaranya: Qur'an-Hadis, Akidah-Akhlak, Fikih, sejarah Kebudayaan Islam, Bahasa Arab dan Baca Tulis Al-Qur'an. Ditemukan 6 materi pelajaran dalam satu buku. Buku ini dicetak oleh CV. Sindunata dengan ukuran sampul kertas kwarto F4, ditulis oleh Puji Prihwanto, dan memiliki ISBN: 978-602-442-353-7 (jilid lengkap) 978-602442-362-9 yang tertera di sampul dalam dan halaman terakhir buku.

\footnotetext{
${ }^{14}$ Hidayah dan Asyrofi, “Analisis Kesalahan Sintaksis Pada Buku Teks Duru>Su AlLughah Al-Ara>Biyah 'Ala> Thoriqotial-Muba>Syarah Al-Muta>Kamilah Karya Muhammad In'Am, M.A," 245.

${ }^{15}$ Eriyanto, Analisis Isi: Pengantar Metodologi Untuk Penelitian Ilmu Komunikasi Dan Ilmu-IImu Sosial Lainnya (Jakarta: Prenada Media Group, 2011), 15.

${ }^{16}$ Suharto dan Fauzi, "Analisis Kesalahan Sintaksis Dalam Buku Teks Bahasa Arab Untuk Perguruan Tinggi Keagamaan Islam," 27.
} 
Temuan selanjutnya adalah ISBN yang tercantum pada buku tidak terdeteksi oleh Perpustakaan Nasional Republik Indonesia . Buku ini terbit tanpa keterangan tahun cetak, dengan editor Amiruddi Fattah, S.Pd.I. dan ilustrator Andika Moch. Basuki, A.Md., setter: Rice Laksitorini dan perancang kulit Budi Santoso. Hal ini berbeda dengan buku bahasa Arab yang dianalisis oleh Toto Suharto, buku bahasa Arabnya memiliki ISBN resmi yang dapat ditelusuri melalui Perpustakaan Nasional Republik Indonesia dan dalam satu buku hanya ada satu materi saja, yaitu bahasa Arab. ${ }^{17}$

Buku ini cukup memiliki kelengkapan informasi. Sampul buku bagian depan bertuliskan "Fokus: Modul Bahan Ajar K13 Bahasa Arab Untuk Madrasah Ibtidaiyah Kelas 5A", berwarna hijau dan putih dengan gambar sebuah masjid. Dapat diketahui gambar tersebut adalah masjid raya Medan. Sampul depan dilengkapi dengan data mata pelajaran yang terdapat pada buku tersebut; 6 mata pelajaran. Pada bagian cover sebelah kanan buku bertuliskan keterangan kelas dan sebelah kiri bagian bawah bertuliskan keterangan "dilengkapi soal HOTS (Higher Order Thinking Skills)". Adapun di sampul bagian dalam berisi keterangan penulis, editor, setter, Ilustrator dan perancang kulit. Diikuti dengan alamat kantor CV. Sindunata, ${ }^{18}$ keterangan penyettingan dan layout dan keterangan nomor ISBN. Pada bagian bawahnya terdapat sebuah kolom kepemilikan buku yang terdiri dari: nama, kelas, nomor absen dan sekolah.

Sampul bagian belakang berlatar belakang warna putih dengan keterangan kelas dan jenjang sekolah yang menggunakan buku tersebut, pernyataan materi isi buku dan alamat dari penerbit lengkap dengan barcode ISBN, walaupun tidak berfungsi. Buku bahan ajar ini berisi pendalaman materi pembelajaran dari masing-masing subjek mata pelajaran yang tercantum, ragam tugas sebagai kegiatan untuk menguji pemahaman materi sekaligus pengembangan keterampilan dan sikap. Selanjutnya dilengkapi juga dengan penilaian autentik yang mencakup ranah sikap, pengetahuan dan keterampilan yang dilaksanakan secara berkala. Adapun di akhir setiap pendalaman materi terdapat soal-soal latihan sebagai ajang persiapan menghadapi penilaian akhir semester. ${ }^{19}$

Peneliti belum bisa mengonfirmasi data ini kepada penulis dan penerbit, sebab para pengajar yang mengadakan buku ini sudah kehilangan kontak

\footnotetext{
${ }^{17}$ Suharto dan Fauzi, "Analisis Kesalahan Sintaksis Dalam Buku Teks Bahasa Arab Untuk Perguruan Tinggi Keagamaan Islam."

18 Alamat kantor CV. Sindunata: Jl. Diponegoro No. 123 Kartasura, Sukoharjo 57166. Telp. (0271) 781 797, 781 853. Fax: (0271) 781 797, Website: http//www.foussindunata.com, email: fokussinduta@gmail.com

${ }^{19}$ Prihwanto, Fokus: Modul Bahan Ajar K13 Bahasa Arab Untuk Madrasah Ibtidaiyah Kelas 5 A.
} 
dengan sales penjual buku ini. Dan ketika peneliti konfirmasi atas alasan memilih buku ini adalah karena faktor harga bersaing dan sales itu datang sendiri ke sekolah. Buku ini dianggap lebih mudah didapat dan terjangkau dibandingkan buku-buku lain. Memang sudah disediakan oleh Kementerian Agama buku bahasa Arab untuk Madrasah Ibtidaiyah yang dapat didownload, namun pengadaan buku dalam bentuk hard copy masih mengalami kendala. ${ }^{20}$

\section{Bentuk-Bentuk Kesalahan Sintaksis}

Berdasarkan analisis kesalahan sintaksis ditemukan pada buku "Fokus: Modul Bahan Ajar K13 Bahasa Arab Untuk Madrasah Ibtidaiyah Kelas 5A" beberapa kesalahan-kesalahan yang perlu diperbaiki. Kesalahan-kesalahan tersebut, peneliti temukan di pendalaman materi dan ragam tugas yang berada di dalam buku. Di bawah ini merupakan kesalahan-kesalahan sintaksis, yang sudah melalui proses identifikasi kesalahan, deskripsi kesalahan dan penafsiran kesalahan:

a. في غرفةُ المذاكرة (hlm. 105). Harakat berada pada kata غرفة yang في terletak setelah huruf jar, yaitu berupa

b. كيف تكون الماء (hlm. 110). Di sini kata الماء bersifat mudzakar diikuti dengan kata kerja yang bersifat muannats yaitu تكون العنان.

c. لون برتقالُ برتقالي (hlm. 112). Merupakan susunan idhofah di mana kata برتنقال adalah mudhofilaih dari kata برن برن memiliki i'rob jar dengan tanda harakat kasrah, karena kata itu termasuk isim mufrod.

d. لون الكرسيُ أسمر (hlm. 112). Kata الكرسيّ ber-harakat dhammah, yang merupakan mudhof ilaih dari kata لوني لون yang berkedudukan menjadi mudhof.

e. لونَ عنبّ بنفسجي (hlm. 112). Kata عنبّ berharokat dhammah tanwin, yang merupakan mudhof ilaih dari kata لون yang berkedudukan menjadi mudhof.

f. السبورة لون اسود (hlm. 112). Kata لون tidak diberi dhamir kepemilikan yang kembali pada kata sebelumnya.

g. موز لون اصعر (hlm. 112). Kata لون juga tidak diberi dhamir yang kembali kepada kata sebelumnya. begitu juga dengan kata اصعر yang memiliki arti makna memalingkan, dan bukan termasuk macammacam nama dari warna.

h. الحفض لون أزرق (hlm. 112). Kata لون juga tidak diberikan dhamir yang kembali kepada kata sebelumnya, begitu juga dengan kata المحفض yang memiliki arti kain lap/popok. Hal ini tidak sesuai dengan gambar pada teks yang berupa tas.

20 Wawancara virtual dengan salah satu guru bahasa Arab yang menggunakan buku ini, dilakukan pada 20 Maret 2020. 
i. ما لون ادارةُ المدرسةّ؟ (hlm. 116). Kata ادارة berharokat dhummah, yang merupakan mudhof ilaih dari kata لون لون الرن لون yang berkedudukan sebagai mudhof.

j. الفي الفصل yang bersambung dengan dhomir ya' padahal terdapat ال فل ال

k. مدرستي في المدينة. للمدرستي فناء واسع (hlm. 117). Di sini terdapat pengulangan kata مدرسة لمسنة yang dapat diganti dengan dhamir ha' alif yang kembali pada madrasati. Demikian juga, kesalahan ya' pada .

Ditemukan sebelas kesalahan sintaksis pada buku tersebut. Kesalahan sintaksis tersebut dapat diklasifikasikan ke dalam tujuh bentuk kesalahan; (1) Kesalahan i'rab pada poin a, d dan i. (2) Kesalahan bentuk fi'il terdapat pada poin b. (3) Kesalahan bentuk idhafah pada poin c dan e. (4) Kesalahan bentuk dhamir pada poin $\mathrm{f}$, g, dan h. (5) Kesalahan bentuk makna kata pada poin h. (6) Kesalahan bentuk ma'rifat pada poin j. (7) Kesalahan pemilihan kata dan pengulangan pada poin k. Bentuk-bentuk kesalahan sintaksis ini juga ditemukan oleh Toto dalam penelitiannya, bahkan ia lebih banyak menemukan pola-pola kesalahan. Di antaranya bentuk-bentuk di atas kemudian bentuk penulisan na'at-man'ut, penulisan athaf-ma'thuf, dan penulisan $n$ ' $^{\prime}$ ibu al-fail. ${ }^{21}$

\section{Tashwib bentuk-bentuk kesalahan Sintaksis}

Temuan di atas telah melalui proses identifikasi kesalahan, deskripsi kesalahan dan penafsiran kesalahan. Pada bagian ini dilaporkan proses revisi (tașwib) bentuk-bentuk kesalahan yang ditemukan di atas. Adapun revisi (tașwib) tersebut dilakukan sesuai dengan kelompok kesalahan.

Pertama, Pembetulan kesalahan bentuk i'rob. I'rob merupakan bentuk perubahan akhir kalimat karena adanya perbedaan amil yang masuk, baik secara lafadz maupun perkiraan (taqdir). Contoh, جَاءَ زَيَدُ "Zaid telah datang”. Kata زَيْن dibaca rofa' dengan tanda dhammah, karena adanya sebuah amil yang menempatkannya sebagai subjek/fa'il. Amil tersebut adalah kata

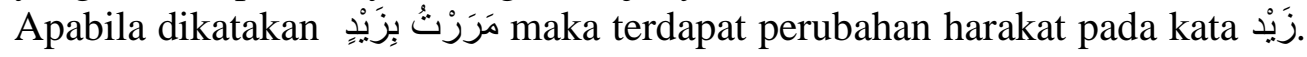
Kata itu berubah bacaan menjadi majrur dengan tanda kasroh. Pada contoh kalimat ini, amilnya adalah huruf ب huruf jar. Demikian seterusnya. I'rob pada isim memiliki tiga bentuk yaitu rafa', nashob, dan jar dengan أن, لن إذًا، amil/tanda yang berbeda-beda. Misalnya amil i'rob nashob adalah dan من، إلى، عن، على، في، رب، ب، ل ، ك ل5 Dan amil bagi i'rob jar adalah لام، كي lainnya. ${ }^{22}$ Dengan demikian, penulisan yang benar yaitu:

${ }^{21}$ Suharto dan Fauzi, "Analisis Kesalahan Sintaksis Dalam Buku Teks Bahasa Arab Untuk Perguruan Tinggi Keagamaan Islam," 31.

22 Muhammad Muhyiddin, Terjemah Syarah Jurumiyah Attuhfah Al-Saniyah Syarah Al-Muqoddimah Al-Ajurumiyah (Johor Baru: Perniagaan Jahabersa, 2019), 25. 


\begin{tabular}{|c|c|c|}
\hline No. & Kesalahan & Revisi \\
\hline 1. & في غرفةُ المذاكرة & في غرفِة المذاكرة \\
\hline 2. & لون الكرسيُّ أسمر & لون الكرسيّ أسمر \\
\hline 3. & ما لون ادارةُ المدرسة؟ & ما لون إدارةٍ المدرسة؟ \\
\hline
\end{tabular}

Pada poin nomor 1, kata fĩ itu menjadi amil terhadap kata setelahnya, maka harus dibaca jar. Poin nomor 2 itu kata الكرسي merupakan bentuk mudhof ilaih yang memiliki i'rob jar berupa kasroh. Dan poin nomor 3 bahwa kata إدارة merupakan mudhaf ilaih dan memiliki i'rob jar berupa kasroh. Kata إدارة juga menggunakan hamzah qata' bukan hamzah wasal.

Kedua, Pembetulan kesalahan bentuk fi'il. Kāna termasuk kata kerja dalam bahasa Arab yang merafa'kan isim dan menashabkan khabar. Contoh كان زيدٌ قائماً، يكون البيثُ ناظفاً . Dalam penggunaan hukum kaana digunakan sesuai dengan dhamir penggunaannya, yaitu mudzakar dan muannats-nya. Seperti contoh: kesalahan dalam buku teks dapat dibenarkan menjadi: كيف يكون الماء الماء Karena kata المكاء bersifat mudzakar sehingga menggunakan kata يكون bukan تكرن يكون.

Ketiga, Pembetulan kesalahan bentuk dhamir. Dhamir adalah bentuk kata ganti dalam bahasa Arab. Dhamir memiliki aturan tetap (mabni), tidak berubah bentuk sama sekali. Karena dhamir ini selalu menggantikan sebuah nama atau benda atau kelompok maka sering disebut isim ma'rifat (nama tertentu) yang mabni. Dhamir ini dibagi menjadi dua; dhamir muttashil dan munfashil. Adapun dhamir munfashil dapat digunakan di awal kata, terdiri atas 12 macam, seperti هو، هما، هم، هي، هما، هن Adapun dhamir muttashil ialah, dhamir yang tidak dapat digunakan di awal kata, yaitu terdiri dari dua belas macam, dalam tiga kategori: 5 ghoib yang berupa: هن هما، هم، هان ، dengan contoh seperti: بيته، بيتها، بيتهما، بيتهم، بيتها، بيتهما، بيتهن

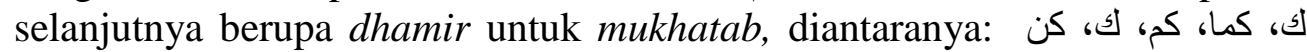
contoh: كتابك، كتابكما، كتابهم، كتابها، كتابكن. Adapun 2 lainnya yaitu digunakan untuk mutakallim wahdah seperti contoh: كتابكي ،كابك yang artinya buku milikku (bukuku), dan ن ن yang digunakan untuk mutakallim ma'al ghair seperti contoh كتابنا. Dari penjelasan tersebut kesalahan yang terdapat di dalam buku bahan ajar dapat dibetulkan menjadi:

${ }^{23}$ Muhyiddin, 123. 


\begin{tabular}{|c|c|c|}
\hline No & Kesalahan & Revisi \\
\hline 1. & في الفصلي & في فصلي \\
\hline 2. & موز لون اصعر & لموز لونه الموز أسمر \\
\hline 3. & المحفض لون أزرق & المفنظة لوها أزرق المحفظة أزرق \\
\hline 4. & السبورة لون اسود & لون السبورة لوها أسود \\
\hline
\end{tabular}

Contoh nomor satu, dapat direvisi dengan di dalam kelas saya. Maka harus dihilangkan lam ta'rif. Sebab tanda isim cukup digunakan satu saja, jika digunakan keduanya akan menjadi salah. Poin nomor dua, pada kata launu terdapat unsur kepemilikan, di mana dalam arti kalimatnya menjadi: "pisang memiliki warna coklat" atau dengan terjemah lain "Pisang itu warnanya coklat". Maka ditambah dhamir ha' mudzakar yang kembali pada kata موز. Dan penambahan alif lam di awal kata mauzun sebagai bentuk keterangan definitif bahwa yang dimaksud yaitu pisang yang terdapat pada gambar teks. Dalam ungkapan warna dalam bahasa Arab ada tiga pilihan kalimat yang sering digunakan orang Arab, seperti contoh di atas.

Analisa poin nomor tiga mirip dengan poin sebelumnya, hanya saja isim yang digunakan berbentuk muannast. Nomor empat juga demikian, hanya saja di sini peneliti berasumsi bahwa penulis buku belum mengerti bahasa Arab dengan benar. Sebab penulis buku mengulang kesalahan yang sama, menerjemahkan langsung kata perkata bahasa Indonesia-Arab (papan tulis itu warna hitam) maka muncullah terjemah pada buku itu. Sebuah terjemahan yang belum disesuaikan dengan kaidah bahasa Arabnya.

Keempat, Pembetulan kesalahan bentuk isim ma'rifat. Penggunaan isim ma'rifat. Isim ma'rifat adalah isim yang menunjukkan sesuatu yang sudah jelas (tertentu). Isim ma'rifat ada lima macam bentuk, diantaranya: 
isim dhomir, isim alam, isim mubham, isim yang diberi alif lam, dan isim yang di-idhofahkan. ${ }^{24}$ Berdasarkan macam-macam di atas, kelimanya adalah bentuk kesatuan dari isim ma'rifat itu sendiri, artinya penggunaan dalam tanda isim ma'rifat ini tidak boleh digunakan bersamaan dalam satu kata sekaligus, karena akan melanggar kaidah bahasa Arab yang baku. Dari penjelasan ini maka penggunaan yang benar adalah: في الفصل bukan في الفصلي. Karena di sana terdapat dua tanda isim ma'rifat sekaligus dalam satu kata, yaitu berupa: alif lam ma'rifat dan isim dhomir berupa kepemilikan yang memiliki arti "saya".

Kelima, Pembetulan kesalahan bentuk kosa-kata. Kesalahan kosakata yang berakibat pada berubahnya makna. Dalam buku tersebut dituliskan bahwa المحفض لون أزرق dengan keterangan gambar tas, artinya kata yang

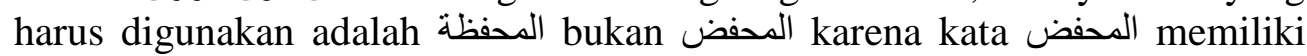
arti kain lap/pembalut, sedangkan kata المحفظة memiliki arti tas/alat untuk menjaga. Kesalahan yang kedua terletak pada kalimat موز لون اصعر. Di sini merupakan sedang membicarakan tentang warna. Dimana kata اصعر memiliki arti memalingkan, dan kata ini tidak masuk ke dalam macammacam warna, melainkan sebuah kata kerja. Jadi pembetulan dalam kata اسمر menjadi أصفر (coklat) ataung).

Keenam, Pembetulan kesalahan bentuk idhofah. Idhofah adalah penyandaran sebuah isim kepada isim lainnya di mana isim yang kedua (disebut dengan mudhof ilaih dibaca majrur. Di dalam idhofah ini dibedakan menjadi tiga macam, yaitu yang ditakdirkan dengan $f i$, ditakdirkan dengan min dan yang menyimpan makna lam (milik). ${ }^{25}$ Contoh: بابُ الفصلِ yang memiliki arti pintu kelas (pintu milik kelas). Maka, beberapa kesalahan idhafah dapat dibenarkan sebagai berikut: لونَ عنبّ بنفسجي dikoreksi menjadi Karena isim yang kedua atau disebut dengan mudhofilaih

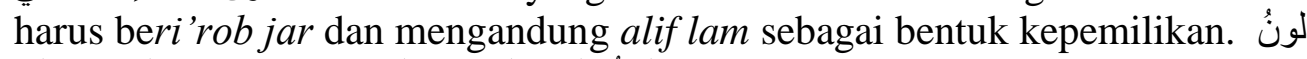

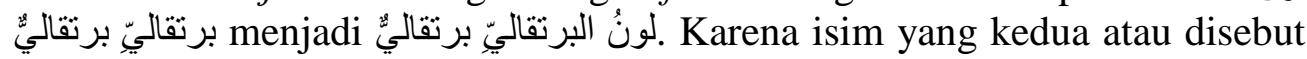
dengan mudhof ilaih harus ber-i'rob jar dan mengandung alif lam sebagai bentuk kepemilikan.

Ketujuh, Pembetulan pengulangan kata. Dhamir digunakan untuk merujuk kata yang sudah disebutkan. Maka, ketika suatu kata sudah disebutkan dan untuk menghindari pengulangan kata di tempat yang berdekatan dapat diganti dengan menggunakan dhamir. Seperti pada contoh berikut; مدرسني في المدينة. للدرستي فناء واسع. Di sini terdapat pengulangan kata مدرسة yang dapat diganti dengan dhamir ha' alif yang kembali pada kata alMadrasah. Maka susunan kalimat tersebut dapat berbentuk dengan kalimat berikut: مدرستي في المدينة، لها فناء واسع.

\footnotetext{
${ }^{24}$ Muhyiddin, 137.

${ }^{25}$ Muhyiddin, 206.
} 


\section{Kritik Terhadap Buku "Fokus"}

Buku bahan ajar "Fokus: Modul Bahan Ajar K13 Bahasa Arab Untuk Madrasah Ibtidaiyah Kelas 5A" merupakan buku bahan ajar yang diterbitkan oleh CV. Sindunata sebagai buku acuan dalam proses pembelajaran Madrasah Ibtidaiyah kelas VA Semester 1. Setelah peneliti menganalisis kesalahan sintaksis, ditemukan tujuh bentuk kesalahan yang terdapat di dalam buku bahan ajar tersebut. Kesalahan-kesalahan di dalam penulisan sebuah buku memang sangat mungkin terjadi, kendati demikian seharusnya hal ini sangat dihindari, mengingat buku bahan ajar tersebut ditujukan untuk pelajar Madrasah Ibtidaiyah, di mana pelajar masih dalam tahap awal dalam pembelajaran bahasa arab. Hal ini akan sangat berbahaya ketika peserta didik memperoleh materi-materi yang salah di dalam pembelajarannya. Hal ini sebaiknya dihindari, guna tidak adanya terjadi kesalahan di dalam pemahaman setiap peserta didik.

Proses penerbitan buku ini diprediksikan belum melalui proses editing sebelum hingga akhirnya diterbitkan dan dipergunakan. Berdasarkan sampul buku bahan ajar kurikulum 2013 Fokus, terdapat nama penulis yang tidak memiliki background bahasa Arab atau Pendidikan Bahasa Arab, juga terdapat nama seorang editor yang bernama Amiruddin Fattah, S.Pd.I. memiliki riwayat pendidikan bahasa Arab di Institut Agama Islam Negeri (IAIN) Surakarta, menempuh pendidikan selama lima tahun, yaitu 2007 sampai 2012. ${ }^{26}$ Sebaiknya editor benar-benar melakukan editing dengan sebaik mungkin, terutama pada bagian kesalahan-kesalahan kebahasaan. Kesalahan kebahasaan di dalam sebuah buku bahan ajar akan mengurangi kualitas buku tersebut, di mana akan berakibat pada hasil dari pemerolehan pembelajaran pada peserta didik. Meskipun kesalahan sintaksis tersebut sedikit, akan tetapi kesalahan-kesalahan tersebut menjadi sebuah aib bagi buku bahan ajar Fokus, tidak hanya itu saja melainkan akan juga menjadikan kurang kepercayaan pengguna kepada percetakan maupun tim Fokus itu sendiri. Dalam pembuatan buku bahan ajar seyogyanya tidak mementingkan kecepatan terselesainya sebuah buku karena alasan proyek, hingga pada akhirnya menyampingkan kualitas dari buku bahan ajar tersebut.

Sebab buku bahan ajar merupakan buku teks yang digunakan untuk membantu pengembangan siswa dalam proses pembelajaran. ${ }^{27}$ Artinya, modul bahan ajar kategori buku teks yang di dalamnya berisi materi-materi pelajaran, disusun secara sistematis untuk mencapai tujuan pembelajaran

${ }^{26}$ Prihwanto, Fokus: Modul Bahan Ajar K13 Bahasa Arab Untuk Madrasah Ibtidaiyah Kelas 5 A.

${ }^{27}$ Nafiah dan Irawati, "Pengembangan Bahan Ajar Bahasa Arab Sebagai Penunjang Pembelajaran Tarakib (Qawaid) Kelas VII MTs Negeri 1 Semarang," 25. 
sesuai dengan kurikulum yang ditetapkan. ${ }^{28}$ Bahan ajar juga merupakan media instruksional yang memainkan peran penting di dalam kelas dan menjadi dominan dalam keberhasilan pembelajaran. Bahan ajar juga berfungsi sebagai penyampai materi sesuai dengan capaian pembelajaran pada kurikulum mata pelajaran, dan juga sebagai motor penggerak untuk meningkatkan mutu pendidikan di tingkat sekolah dan madrasah. Maka, kiranya perlu kebijakan pemerintah dalam menentukan bahan ajar dalam bentuk buku ajar atau buku teks yang tepat guna bagi madrasah dalam menyelenggarakan pendidikan kepada para peserta didik. ${ }^{29}$

Kemudian buku "Fokus: Modul Bahan Ajar K13 Bahasa Arab Untuk Madrasah Ibtidaiyah Kelas $5 A$ " belum memiliki karakter buku teks bahasa Arab yang digunakan untuk siswa non-Arab, seperti karakteristik bahasa, karakteristik budaya, karakteristik psikologi dan karakteristik geografis. Penulis buku teks bahasa Arab minimal harus mempertimbangkan beberapa aspek berikut, Pertama, Aspek Sosial Budaya, hubungan dan keterkaitan antara bahasa dan budaya ini tidak dapat dipisahkan karena ia bersifat dialektis. Sebab tidak ada budaya tanpa bahasa, demikian juga sebaliknya tidak ada bahasa tanpa budaya. Bahasa Arab memiliki ciri khas budaya yang kuat. Budaya Arab dan budaya Islam tidak dapat dipisahkan dari bahasa ini, maka para pelajar non-Arab tidak dapat menghindari budaya itu saat mempelajari bahasa Arab. Hal ini terjadi karena dalam linguistik sosial yang terkadang akan menggiring pada sebuah logat tertentu seperti Arab Saudi, Mesir, Sudan dan lainnya. ${ }^{30}$ Oleh karena itu, pelajar bahasa asing diharuskan untuk mengenal budaya masyarakat pemilik bahasa yang akan dipelajari itu.

Kedua, Aspek Psikologis Siswa. Di dalam menulis dan mempersiapkan buku pendidikan -baik bahasa atau lainnya-, penulis harus mempelajari karakteristik siswa dari sudut pandang psikologis dan mental siswa. Adanya dorongan dan motivasi merupakan sebuah ciri khas pembelajaran bahasa asing bagi siswa, karena dalam pembelajaran bahasa asing tidaklah mudah, sebab di dalamnya terdapat proses mental dan usaha yang maksimal disertai dengan kesabaran. Ketiga, Aspek Kebahasaan, pengertian bahasa sebagai satuan sistem fonetik, morfologi, gramatikal begitu pun leksikal yang

${ }^{28}$ Baroroh dan Tsani, “Evaluasi Mahārah Al-Qirā’ah Dalam Buku Ajar Durūs AlLugah Al-'Arabiyyah Buku Siswa Bahasa Arab Pendekatan Saintifik Kurikulum 2013 Kelas X Madrasah Aliyah," 109.

${ }^{29}$ Hidayah dan Asyrofi, "Analisis Kesalahan Sintaksis Pada Buku Teks Duru>Su AlLughah Al-Ara>Biyah 'Ala> Thoriqotial-Muba>Syarah Al-Muta>Kamilah Karya Muhammad In'Am, M.A," 239.

${ }^{30}$ Mirwan Ahmad Taufiq, "Asbab At-Tahadduts Bi Al-Arabiyah As-Suqiyah (Dirasah Mashiyah Lughawiyah Ala Talamidz Madrasah Al-Asas)," Jurnal Alfazuna : Jurnal

Pembelajaran Bahasa Arab Dan Kebahasaaraban 1, no. 1 (2016): 1-20, http://jurnalftk.uinsby.ac.id/index.php/alfazuna/article/view/3. 
disusun demi menghasilkan kalimat dan makna antara kelompok-kelompok golongan tertentu menjadi acuan utama penyusunan buku teks bahasa Arab. Di mana di dalamnya berisi cakupan dasar-dasar linguistik kebahasaan yang meliputi bunyi/suara, mufradat/kosakata dan struktur bahasa yang disesuaikan dengan tingkat mental dan tingkat kebahasaan peserta didik. ${ }^{31}$ Dalam hal ini, penyusunan buku teks sangat membutuhkan kejelian tinggi dalam hal aspek kebahasaan di mana pemilihan kosakata dan gramatika yang tepat akan menjadi nilai junjung yang tinggi dalam menyampaikan peserta didik mencapai tujuan dari kurikulum yang ditetapkan. Keempat, Aspek Kependidikan. Pelajar yang akan mempelajari bahasa Arab tentu akan berlandaskan nilai guna yang akan dimanfaatkannya. Nilai guna ini akan tergambarkan dengan jelas pada $\mathrm{CP}$ yang akan ditarget. $\mathrm{CP}$ yang bersifat umum akan menghasilkan sebuah buku bahasa Arab untuk kehidupan, seluruh tema akan ditampilkan dalam setiap bab-babnya. CP yang bersifat khusus akan melahirkan buku-buku untuk tujuan khusus, seperti bahasa Arab untuk turis, Bahasa Arab untuk Haji dan Umrah. Model buku yang kedua ini sering disebut sebagai Arabic for Specific Purpose (ASP). ${ }^{32}$

Hal penting selanjutnya adalah kurangnya fokus kajian buku tersebut. Sebab tidak hanya memuat materi bahasa Arab saja, tapi juga beberapa mata pelajaran lainnya. Fokus yang bercabang ini berimplikasi pada kualitas materi secara substantif dalam kandungan sebuah buku bahan ajar. Seharusnya buku ini ideal fokus satu bidang satu buku, sebagaimana namanya "Fokus".

\section{Kesimpulan}

Ditemukan tujuh bentuk kesalahan sintaksis pada buku "Fokus: Modul Bahan Ajar K13 Bahasa Arab Untuk Madrasah Ibtidaiyah Kelas 5A", yaitu: susunan kata, susunan idhafah, salah penggunaan kosakata, kesalahan penggunaan al-ta'rif, i'rob, dhamir, dan kesalahan penggunaan bentuk fi'il. Dari tujuh bentuk kesalahan tersebut, kesalahan terbanyak terletak pada penggunaan dhamir, yaitu terdapat empat kesalahan. Adapun kesalahan lainnya seperti susunan kata terdapat satu kesalahan, penerapan idhofah terdapat dua kesalahan, penggunaan kosakata dua kesalahan, al-ta'rif satu kesalahan, $i$ 'rob tiga kesalahan dan kesalahan penggunaan $f i$ 'il terdapat satu kesalahan. Analisis konten yang digunakan dengan menggunakan teknik analisis kesalahan gabungan milik Rusydi dan al-Rajihi dapat mengungkap

\footnotetext{
${ }^{31}$ Sutri Ramah dan Miftahur Rohman, "Analisis Buku Ajar Bahasa Arab Madrasah Aliyah Kurikulum 2013," Arabiyatuna : Jurnal Bahasa Arab 2, no. 2 (26 Desember 2018): 141-60, https://doi.org/10.29240/jba.v2i2.552.

32 Mirwan Akhmad Taufiq, Al-Arabiyah Li Bi'tsah Al-Hajj Al-Indunisiyah (Bahasa Arab untuk Petugas Haji Indonesia) (Surabaya: JDS, 2018), 2, http://digilib.uinsby.ac.id/32375/.
} 
kesalahan-kesalahan Nahwu dan melakukan pembetulan sesuai dengan bentuk kesalahannya. Kemudian nomor ISBN buku ini tidak dapat dilacak di perpusnas Indonesia. Penulis tidak memiliki spesifikasi keahlian dalam bidang Pendidikan Bahasa Arab. Namun, editor memiliki spesifikasi tersebut. Walaupun demikian, buku ini tetap digunakan di beberapa madrasah karena faktor sales buku jemput bola dan harga terjangkau. Temuan ini seirama dengan hasil penelitian Toto, hanya saja buku yang menjadi objek sudah terdeteksi di Perpustakaan Nasional Republik Indonesia dan kesalahan-kesalahan itu terjadi karena faktor cetak dan terbit cepat karena buku segera digunakan, bukan faktor komersial buku seperti di atas.

Peneliti menyarankan kepada para penulis buku bahasa Arab agar menghindari kesalahan dalam penulisan buku bahan ajar, karena mutu dari buku bahan ajar tersebut akan turun, yang berakibat pada mutu anak didik saat belajar bahasa Arab. Saran kedua, para peneliti dapat melakukan penelitian analisis teks terhadap buku-buku pendidikan bahasa Arab di semua tingkat pendidikan, baik itu dalam bentuk buku bacaan, buku bahan ajar, LKS dan lain. Diharapkan dari penelitian ini dapat mengungkap sisi kualitas setiap buku-buku tersebut. Gelombang penerbitan buku bahasa Arab diprediksikan akan terus muncul dan bertambah, sebab terdapat nilai material untuk dapat dikomersialkan. Posisi para peneliti menjadi garda kontrol kualitas dari buku-buku tersebut. Selain analisis kesalahan sintaksis, dapat dilakukan analisis kesalahan yang lain dan analisis teks lainnya. 


\section{Daftar Pustaka}

Alawiyah, N. Lalah, Ahmad Royani, dan Mukhshon Nawawi. "Analisis

Terjemahan Teks Akademik Mahasiswa Program Studi Pendidikan

Bahasa Arab." Arabiyat : Jurnal Pendidikan Bahasa Arab dan

Kebahasaaraban 3, no. 2 (2016): 217.

https://doi.org/10.15408/a.v3i2.4642.

Baroroh, R. Umi, dan Etika Riani Tsani. "Evaluasi Mahārah Al-Qirā'ah Dalam

Buku Ajar Durūs Al-Lugah Al-'Arabiyyah Buku Siswa Bahasa Arab

Pendekatan Saintifik Kurikulum 2013 Kelas X Madrasah Aliyah." Al

Mahāra: Jurnal Pendidikan Bahasa Arab 5, no. 1 (2019): 101.

https://doi.org/10.14421/almahara.2019.051-06.

Dewi, Annisa Anita. Buku Sebagai Bahan Ajar: Sebuah Perbandingan Buku

Teks Bahasa Inggris di Indonesia dan di Thailand. Sukabumi: CV.

Jejak, 2009.

Eriyanto. Analisis Isi: Pengantar Metodologi Untuk Penelitian IImu

Komunikasi Dan IImu-IImu Sosial Lainnya. Jakarta: Prenada Media

Group, 2011.

Fisiak, Jacek. "The Contrastive Analysis of Phonological Systems." John

Benjamins Publishing Company, 1981.

https://doi.org/10.1075/cilt.12.18fis.

Hidayah, Ihdatul, dan Syamsuddin Asyrofi. "Analisis Kesalahan Sintaksis

Pada Buku Teks Duru>Su Al-Lughah Al-Ara>Biyah 'Ala> Thoriqotial-

Muba>Syarah Al-Muta>Kamilah Karya Muhammad In'Am, M.A." Al

Mahāra: Jurnal Pendidikan Bahasa Arab 4, no. 2 (2018): 239.

https://doi.org/10.14421/almahara.2018.042-05.

Lathifah, Fitria, Syihabuddin Syihabuddin, dan M. Zaka Al Farisi. "Analisis

Kesalahan Fonologis Dalam Keterampilan Membaca Teks Bahasa

Arab." Arabiyat : Jurnal Pendidikan Bahasa Arab dan

Kebahasaaraban 4, no. 2 (2017): 174.

https://doi.org/10.15408/a.v4i2.6273.

Menteri Pendidikan Dan Kebudayaan Republik Indonesia. Peraturan

Menteri Pendidikan Dan Kebudayaan Republik Indonesia Nomor 8

Tahun 2016 Tentang Buku Yang Digunakan Oleh Satuan Pendidikan (2016).

Muhyiddin, Muhammad. Terjemah Syarah Jurumiyah Attuhfah Al-Saniyah

Syarah Al-Muqoddimah Al-Ajurumiyah. Johor Baru: Perniagaan Jahabersa, 2019.

Nafiah, Khotimatun, dan Retno Purnama Irawati. "Pengembangan Bahan

Ajar Bahasa Arab Sebagai Penunjang Pembelajaran Tarakib (Qawaid) 
Kelas VII MTs Negeri 1 Semarang." Lisan Al-Arab : Journal of Arabic Language And Arabic Teaching 4, no. 1 (2015): 23-28.

https://journal.unnes.ac.id/sju/index.php/laa/article/view/7628.

Prihwanto, Puji. Fokus: Modul Bahan Ajar K13 Bahasa Arab Untuk

Madrasah Ibtidaiyah Kelas 5A. Surakarta: CV. Sindunata, 2017.

Ramah, Sutri, dan Miftahur Rohman. "Analisis Buku Ajar Bahasa Arab

Madrasah Aliyah Kurikulum 2013." Arabiyatuna : Jurnal Bahasa Arab

2, no. 2 (26 Desember 2018): 141-60.

https://doi.org/10.29240/jba.v2i2.552.

Suharto, Toto, dan Ahmad Fauzi. "Analisis Kesalahan Sintaksis Dalam Buku

Teks Bahasa Arab Untuk Perguruan Tinggi Keagamaan Islam."

Arabiyat : Jurnal Pendidikan Bahasa Arab dan Kebahasaaraban 4, no. 1 (2017): 20-37. https://doi.org/10.15408/a.v4i1.5274.

Taufiq, Mirwan Ahmad. "Asbab At-Tahadduts Bi Al-Arabiyah As-Suqiyah

(Dirasah Mashiyah Lughawiyah Ala Talamidz Madrasah Al-Asas)."

Jurnal Alfazuna : Jurnal Pembelajaran Bahasa Arab Dan

Kebahasaaraban 1, no. 1 (2016): 1-20.

http://jurnalftk.uinsby.ac.id/index.php/alfazuna/article/view/3.

Taufiq, Mirwan Akhmad. Al-Arabiyah Li Bi'tsah Al-Hajj Al-Indunisiyah

(Bahasa Arab untuk Petugas Haji Indonesia). Surabaya: JDS, 2018.

http://digilib.uinsby.ac.id/32375/.

Widodo, Chomsin S., dan Jasmadi. Panduan Menyusun Bahan Ajar Berbasis Kompetensi. Jakarta: Kompas Gramedia, 2008. 